\title{
POPULAÇÕES TRADICIONAIS NO NORTE DE MINAS GERAIS: SUAS RELAÇÕES, PLURALIDADES SOCIOESPACIAIS NO CAMPO, SABERES E FAZERES
}

\author{
Cássio Alexandre da SILVA \\ Marcela Alves FONSECA ${ }^{2}$ \\ Ana IvaniaAlves FONSECA
}

\section{Resumo}

O artigo apresenta a pluralidade étnico cultural e identidade sertaneja do norte de Minas Gerais nas suas relações socioespaciais no campo. São os indígenas, quilombolas e geraizeiros. Povos originários e Populações Tradicionais que diante da sua cultura ancestral "marcam" uma identidade constituída em práticas com a terra. O processo de territorialidades em suas vidas, apresenta-se cotidianamente. São as condições climáticas, intervenções e/ou conflitos com o Estado e outros interessados nas terras que fazem desses povos a condição de plural. As pluralidades apresentadas recriam distintas territorialidades, saberes e fazeres, economias e lógicas sociais no campo, uma relação diferenciada com o Desenvolvimento Social, o que não é comum na economia capitalista. A metodologia investiga literaturas históricas do vale do São Francisco, identificando e contrapondo os arranjos produtivos econômicos da atualidade sobre o cultivar. A oralidade sustenta os saberes e fazeres de muitas comunidades, assim, o levantamento de dados qualitativos aconteceu através de visitas de campo e encontros de associações locais e regionais. Entendemos que essas relações socioespaciais ao longo de décadas ou até mesmo seculares, mantêm "viva" a cultura identitária sertaneja, dos saberes e fazeres dos índios, negros de quilombos e geraizeiros.

Palavras-chave: Pluralidade. Cultura. Territorialidades. Saberes e Fazeres.

\footnotetext{
Docente do Programa de Pós-Graduação em Geografia- PPGEO/ UNIMONTES. E-mail: cassioas27@gmail.com

2 Graduanda em Geografia pela Universidade Estadual de Montes Claros-UNIMONTES. E-mail: marcela.alvesfonsec@hotmail.com

3 Docente do Programa de Pós-Graduação em Geografia- PPGEO/ UNIMONTES. E-mail: anaivania@gmail.com
} 


\section{Abstract}

\section{Traditional populations from Northern Minas Gerais: Their relations and socio-spatial pluralities on the countryside, know how}

This article presents the cultural-etnic diversity and "sertanejo" identity from northern Minas Gerais in the socio-spatial countryside relations. The Indigenous, quilombolas and "geraizeiros". Traditional populations that with their ancestral culture, keep an identity build in land practice. What the territoriality process in their lives, daily presents are by climatic conditions, conflicts or interventions with the State, and others interesteds on these people lands. The pluralities presented here rebuilt different territorialities, know how, economy and social logics on the countryside, a differentiated relation with social development, which are not usual on this capitalistic economy. This Method investigate historical literature from the São Francisco vale recognizing the nowadays prolific economic arrangements about cultive. The speech keeps the know how of many populations, doing this way the qualitative data-base that happens through countryside visits and local association reunions. We understand that this socio-spatial relations through times keeps vivid the "sertanejo" culture, the indigenous know how, negros from the quilombos and "geraizeiros".

Key words: Plurality. Culture. Territoriality. Knowhow.

\section{INTRODUÇÃO}

O campo de estudo no norte de Minas é amplo em suas etnias, grupos culturais, fazeres e saberes. Nas diversas possibilidades de misturas raciais e étnicas, no chamado Sertão norte-mineiro encontramos uma cultura sertaneja, que para Costa (1997) é:

[...] o resultado do caldeamento de modos de comportamento, relações, saberes e fazeres de etnias diferenciadas que se colocaram em contato no território norte-mineiro bem como as transformações verificadas, com o passar do tempo, em função das articulações das populações existentes como homens de outras regiões. (COSTA, 1997, p.82).

Ao longo da história entre índios, negros e europeus, o espaço ganha funções deixando de ser o vazio: - o sertão. Para além desse vazio, entendemos o sertão como um espaço determinista, com suas características geográficas próprias (clima, relevo, vegetação e hidrografia) e possibilistas, rico em peculiaridades humanas.

Sendo a terra, a matriz principal de toda a população, a luta e resistência por ela torna-se uma estratégia social. As organizações sociais também são construídas e reinventadas, como bem posiciona Brandão (2009, p.36), na afirmação sobre indígenas, negros quilombolas e comunidades camponesas dizendo que, "Onde parece haver uma uniformização crescente e irreversível, podemos estar diante, também, de uma crescente diferenciação de formas culturais de vida e modos sociais de trabalho no campo".

São muitas às mudanças diante do processo histórico entre a tradição e a modernidade, pensando-se na organização socioespacial (ambientais, econômicos, políticos e socioculturais) e o mundo globalizante.

De acordo com Fernandes (2008, p. 215), "O Desenvolvimento Territorial Rural (DTR) acontece por meio de um processo geográfico denominado TDR (territorialização- 
desterritorialização-reterrritorialização), caracterizando uma multiterritorialidade, em que se observam os processos integralizadores, que também são excluidores e ressocialidadores".

No processo histórico da formação e organização sócio territorial no norte de Minas Gerais é imprescindível a concepção e presença da institucionalização do aparelho estatal, que para Clastres, (2003, p.220), "O Estado, dizem, é o instrumento que permite à classe dominante exercer sua dominação violenta sobre as classes dominadas". Nas observações preliminares sobre o conceito de Estado, Giddens (2001) diz que:

O "Estado" possui dois sentidos na linguagem comum, mas a ambigüidade não é particularmente preocupante para a teoria social. Algumas vezes ele significa um aparato do governo ou de poder, outras, é o sistema social como um todo subordinado a esse governo ou poder. Normalmente esses dois sentidos não são confundidos, mas deve-se observar se existe uma distinção terminológica entre eles. (GIDDENS, 2001, p. 42).

Com a configuração espacial em lógicas legais perante o Estado, a terra passa para a condição de território, com limites, posses, demarcações, fronteiras e políticas. Em 1850, a 'Lei de Terra', apresentou-se como o ponto de partida para ampliar o direito de todos. Conforme Godelier (1984) citado por Haesbaert (2004) define território a partir de processo de controle e usufruto dos recursos:

Designa-se por território uma porção da natureza e, portanto, do espaço sobre o qual uma determinada sociedade reivindica e garante a todos ou a parte de seus membros direitos estáveis de acesso, de controle e de uso com respeito à totalidade ou parte dos recursos que aí se encontram e que ela deseja e é capaz de explorar. (GODELIER, 1984, apud HAESBAERT, 2004, p.112).

Para Haesbaert (2004, p.40), há três territórios básicos: o político, o cultural e o econômico, mas daremos ênfase ao "Cultural (muitas vezes culturalista) ou simbólico-cultural; $[\ldots]^{\prime \prime}$.

Com a "chegada" do Estado e suas políticas de planejamento desenvolvimentistas, diversas populações apresentam-se ameaçadas em seus territórios. Os conflitos acentuam-se. Desde posses e grilagens, até mesmo a criação institucionalizada de áreas de preservação e conservação ambiental, como é o caso das Unidades de Conservação-UC, conforme o Sistema Nacional de Unidade de Conservação-SNUC.

As matrizes identitárias sertanejas, Indígenas, Negros de Quilombo e Geraizeiros serão aqui apresentadas não na sua totalidade, mas, como parte do processo socioespacial da região.

\section{DESENVOLVIMENTO}

A socioespacialização do norte de Minas Gerais é condicionada temporalmente por dois momentos distintos, sendo um anterior aos projetos desenvolvimentistas do Estado e o outro posterior. É na contraposição desses instrumentos e nas condições 
vivenciadas que compreendemos as condições de (en)volvimento e (des)envolvimento. Para Fonseca (2014, p.74), "Na atualidade, encontra-se, tanto no resgate da origem dessas populações quanto nos projetos do governo, uma busca por entender essa configuração que se deu nessa parte de Minas Gerais, a qual se difere das demais regiões em buscar o reconhecimento da sua diversidade". Apresentamos alguns desses elementos em cada uma das populações a seguir.

\section{INDÍGENAS: RESISTÊNCIA E LUTA CONTÍNUA PELA TERRA...}

No norte de Minas Gerais, na margem esquerda do rio São Francisco, desde 1728 , os índios da etnia Xakriabá apresentam-se como o maior agrupamento de pessoas que resistiram até a atualidade. Lembramos aqui dos povos Cariri e Tuxá ${ }^{4}$ em Pirapora, dos Caiapós em São Francisco e São Romão que não configuraram essa mesma realidade. Para Costa (2005, p.310) "O modo de uso Xakriabá sobre o seu território se estabeleceu nos moldes da economia regional, sertaneja e cabloca, e suas atividades produtivas constituem-se basicamente da plantação de roças, da criação de animais e coleta extrativista destinadas ao auto-consumo". Nas condições adversas climáticas da região, os Xakriabá vivem e resistem em dois biomas, o Cerrado e a Caatinga. É na Terra Indígena-T.I. que a população ${ }^{5}$ de mais de 9.000 pessoas convivem com a seca, amparando-se em formas culturais ancestrais, aliadas às práticas ambientais da agricultura familiar moderna, usos de tecnologias sociais e políticas públicas de maneira geral. A base do território consiste nas Multidimensões Territoriais - Modos de Tratamento e Intervenções dos Povos: Cultural; Político e Ambiental, conforme Silva (2014). As intervenções apresentam-se com os vários saberes e fazeres ancestrais. Os saberes culturais perduram por centenas de anos, já que a oralidade está implícita na permanência e resistência desses conhecimentos. Para os indígenas não há cultura sem território.

Para Almeida (2008, p.58) "O território é, antes de tudo, uma convivialidade, uma espécie de relação social, política e simbólica que liga o homem à sua terra e, simultaneamente, estabelece sua identidade cultural". É essa a Cultura que incorpora as territorialidades nas dimensões materiais e imateriais.

Reconhecer essa consciência coletiva sobre o território é poder dominar seus lugares; modificar suas paisagens ao critério das necessidades; conviver com os mistérios naturais; acessar os recursos disponíveis; preservar e conservar esses recursos. O índio é agente desse processo de consciência. (SILVA, 2014, p.174).

Das inúmeras experiências e reconhecimento desse processo de consciência, apresentamos algumas das convivências e formas de empoderamentos do território e suas territorialidades. São revelados os fazeres e práticas ambientais como: as

\footnotetext{
4 Os Cariri não mais habitam essa região, e os Tuxá encontram-se em reconstituição do seu território, mas em número reduzido em relação aos Xakriabá. (nota dos autores, 2017).

5 Conforme o Censo do IBGE (2010) a população do município é de 11.715 habitantes. Instituto Brasileiro de Geografia e Estatística - IBGE. Os indígenas no Censo Demográfico 2010 - primeiras considerações com base no quesito cor ou raça. Ministério do Planejamento, Orçamento e Gestão/ Diretoria de Pesquisas. Rio de Janeiro: 2012, p.5. Disponível em: <http://www.ibge.gov.br/ indigenas/indigena_censo2010.pdf>. Acesso em: $15 \mathrm{dez} .2012$.
} 
tecnologias sociais de barraginhas; plantios de mudas em viveiros; cercamentos e proteção das nascentes e bancos de sementes nativas e crioulas.

Destaca-se a utilização de barraginhas, que além de armazenamento de água evitam erosão e abastecem, mesmo que a longo prazo, o lençol freático local e regional. São também construídas as caixas-d'água pela Cáritas Diocesana, juntamente com o apoio do governo federal em programas de convivência com a seca. Em localidades de maior vulnerabilidade do recurso hídrico, recorre-se a utilização de carropipa, feitos pela Fundação Nacional de Saúde (FUNASA).

O fortalecimento desse trabalho cotidiano acontece principalmente nos períodos das secas prolongadas. Conforme Silva (2014), na Aldeia Barreiro Preto existe a interlocução com vários parceiros: Fundo Nacional do Meio Ambiente (FNMA), Centro de Agricultura Alternativa (CAA), UFMG e outros. Destaca-se o projeto "Água e Vida", com o cercamento de 15 nascentes. Aliados aos projetos ambientais, existem os de coexistência às necessidades sociais, como o projeto de confecção de tijolos a base de areia e cimento.

Com relação aos aspectos culturais, na Aldeia Sumaré I, a Casa de Cultura é um empreendimento onde acontece manifestações coletivas como feiras, danças e aulas, além de abrigar uma Rádio Comunitária. Foi construída em parceria com a Universidade Federal de Minas Gerais-UFMG, Secretaria Estadual Cultura e a do município, juntamente com a Organização Não-Governamental-ONG italiana ISCOS, Emília Romagna da Província de Modena e a ANAI, no Brasil. A arquitetura é baseada em estilo indígena de arena. As tecnologias sócias, indubitavelmente, contribuem para a afirmação do povo sobre o seu território.

Na saúde, o destaque é para o projeto da Casa de Medicina Tradicional Xakriabá, onde se revivem os saberes tradicionais dos antepassados e dos mais velhos. Nela, existem as convivências e experiências de parcerias entre tais saberes com o conhecimento das universidades, em específico a UFMG. Outra parceria funcional é também a do Conselho Indigenista Missionário (CIMI), que realizou em 1996-1997 o Encontro das Mulheres Indígenas na cidade de Manga. Nesse encontro, reuniram-se muitas senhoras detentoras de saberes, rezadeiras, parteiras e raizeiras que ajudam nas curas de enfermidades, através do trato de ervas conhecidas ancestralmente.

Com políticas, as formas de organização sociais remontam a consistência entre a tradição e a modernidade.

Criar o espaço-do-habitar equivale a erguer do chão um lugar que conquistamos, de que nos apropriamos e que transformamos, como querem alguns. Um espaço político, pois ali uma polis se instaura. Um espaço econômico, pois ali se produzem os bens da terra (as coisas da natureza tornadas objetos de cultura), ali eles circulam e ali, no mercado para onde de um modo ou de outro todos convergem, e onde são trocados bens, serviços e sentidos" (BRANDÃO, 2009, p.21)

Essas trocas de bens, serviços e sentidos assinalados por Brandão (2009), são oportunidades que os indígenas incorporam aos seus espaços a partir das inúmeras formas e condições políticas.

Muitas das políticas públicas são somatórias para o envolvimento e desenvolvimento dentro e fora da T.I. Dentre as várias representativas políticas, destacamos o Decreto $n^{\circ} 7.747$ de 05 de Junho de 2012 que institui a Política Nacional de Gestão 
Territorial e Ambiental de Terras Indígenas-PNGATI ${ }^{6}$. Os produtos-relatórios que foram a partir dos Projetos GATI $^{7}$ e PNGATI, via edital, trouxeram excelentes resultados principalmente no campo de formação do indígena pesquisador, momento em que estes são sujeitos ativos e reconhecedores de sua identidade e cultura. Inúmeros mapas (etnomapeamentos), foram produzidos pelos próprios indígenas envolvidos com as tecnologias modernas de geoprocessamento. Essa relação entre a tradição e a modernidade é afirmada nas palavras a seguir: "Os Xakriabá tem uma visão holística de mundo. Para eles ambiente, cultura, saúde, educação, história e política estão interligados. Para falar de saúde, falam das matas; para falar de cultura, falam da colheita do milho; para falar de água falam de história e assim por diante" (PNGATI, 2016, p.42). ${ }^{8}$ A garantia dessas políticas juntamente com os saberes e fazeres, estão diretamente aliados e serão reconhecidos com a reconstituição do território que margeia o rio São Francisco.

\section{NEGROS DE QUILOMBOS: QUASE UMA BAHIA NORTE-MINEIRA...}

Os negros de quilombos estão por grande parte do território do norte de Minas Gerais. A sua importância na constituição do mesmo é tão antiga quanto a dos indígenas. A presença numérica de homens e mulheres negras fica expressiva nas "Minas" onde o ouro e o diamante tinha exclusividade de sua mão de obra. Nos "Gerais", nas fazendas de gado e nos plantios eles também eram funcionalmente produtivos.

Os quilombos se constituíram, sem dúvida, no espaço mais expressivo desses movimentos de resistência, seja pela sua significação em termos de distribuição geográfica e histórica, ao longo de todo aquele século, seja pela sua importância referente à participação numérica, em especial tratandose da rebelião do polo dominado das Minas Gerais do período. (RIBEIRO, 2005, p.291).

Muitos dos quilombos estão diretamente vinculados às políticas públicas. 0 reconhecimento de seus territórios e condições sócio culturais estão embasados em laudos antropológicos e auto reconhecimento. Quilombos como os de Brejo dos Crioulos em São João da Ponte (MG); Quilombo da Lapinha em Matias Cardoso (MG) e o de Buriti do Meio em São Francisco (MG), somam a outras dezenas de territórios com suas representações materiais e imateriais da rica cultura negra em nossa região. As inúmeras territorialidades estão vinculadas às desterritorialidades e reterritorialidades, conforme os momentos e relações com o Estado e seus conflitantes. Como

\footnotetext{
${ }^{6}$ Artigo primeiro-Art.10: fica instituída a Política Nacional de Gestão Territorial e Ambiental de Terras Indígenas -PNGATI, com o objetivo de garantir e promover a proteção, a recuperação, a conservação e o uso sustentável dos recursos naturais das terras e territórios indígenas, assegurando a integridade do patrimônio indígena, a melhoria da qualidade de vida e as condições plenas de reprodução física e cultural das atuais e futuras gerações dos povos indígenas, respeitando sua autonomia sociocultural, nos termos da legislação vigente. BRASIL, Decreto $n^{0} 7.747$, de 5 de Junho de 2012 - Institui a Política Nacional de Gestão Territorial e Ambiental de Terras Indígenas - PNGATI. Presidência da república - Casa Civil - Subchefia para Assuntos Jurídicos, 2012 .

7 Gestão Ambiental e Territorial Indígena- GATI, 2014.

8 PNGATI - Plano de Gestão Territorial e Ambiental das Terras Indígenas do Povo Xakriabá e Xakriabá Rancharia - Produto 3 - BRA/13/019 - Implementação da PNGATI (2016, p.42)
} 
exemplificação, trazemos o Brejo dos Crioulos, amplamente narrado e contextualizado por Salgado (2015):

Na trijunção dos municípios de São João da Ponte (MG), Varzelândia (MG) e Verdelândia (MG) aproximadamente três mil pessoas em seiscentos e oitenta e quatro famílias vivem historicamente em situações desafiadoras da subsistência, auto identificação identitária e reconhecimento territorial em virtude da complexidade envolvida no território Quilombola que historicamente vivem a produzir. Nesse sentido, a zona de contato entre os recortes expões os limites já quase insuperáveis tanto da resiliência sociespacial do território mimetizado em resistência, quando do esgotamento estrutural dos arranjos capitalistas nele estabelecidos, uma vez consolidados pela imposição da ordem hegemônica dos desarranjos sociais, econômicos, ambientais, culturais e políticos no lugar de viver dos Quilombolas de Brejo dos Crioulos. (SALGADO, 2015, p.39-40)

Muitos dos demais quilombos na região têm como exemplo a concepção e as estratégias de luta de Brejo dos Crioulos, pois foram vários os momentos e principalmente as mudanças nas legislações.

Sobre o olhar das formas e lidas cotidianas no campo, "o povo do Brejo", como são denominados, tem suas bases nos plantios tradicionais. A manutenção das roças está diretamente associada aos ciclos das secas e das águas.

De modo geral as famílias vivem a agricultura familiar, plantando em pequenas glebas de terra, principalmente, arroz, feijão, madioca, cana, pimenta, entre outros, além da criação de pequenos animais. A maioria delas possui uma pequena unidade produtirva, com alguns moradores não possuindo terras. A principal atividade econômica é voltada para a produção agrícola, animal e extrativista para subsistência e venda de excedentes nasfeiras de Varzelândia e São João da Ponte (SALGADO, 2015, p.221-222).

Os inúmeros ambientes e paisagens nas comunidades do Brejo dos Crioulos, perfazem os vários usos e multifuncionalidades dos espaços no meio rural. Em cada condição da fisiologia e da fisionomia da paisagem, se estabelecem muitas outras possibilidades de dinâmicas dos modos e experiências vivenciadas.

Na condição atual de um território demarcado, ainda com a "liberdade" transitória, existem várias ameaças que rondam às fronteiras tanto materiais quanto imateriais. Dessas fronteiras materiais ainda fazem parte ameaças de fazendeiros e posseiros e dos "modelos" socioespaciais empregados por esses, como as formas e meios de lida no campo. Já, nas fronteiras imateriais, a constante sensação dos "assédios", sendo o moral, o de maior incômodo ao grupo social reafirma a sua indivisibilidade.

Nessa "tênue linha" de manutenção da tradição com as inúmeras transformações da modernidade, os sujeitos são, tanto "os de dentro" quanto "os de fora", marcados por suas identidades frente ao mundo vivido. 


\section{OS GERAIZEIROS: GERAIS COMUNS...}

Das divisões territoriais das Capitanias, para às Sesmarias e às grandes fazendas, ainda em imensas dimensões, qualificam-se os Gerais. Na condição de grandes espacialidades e vazios essas terras denominadas de gerais, adquirem uma interessante configuração de povoamento. Os grupos denominados aqui de geraizeiros, mesmo distante de seus demais pares convivem de forma comum dos recursos advindos do Cerrado e da Caatinga. "É que Campos Gerais indicam um modo de uso, um modo de apropriação comum, geral, das terras. Indica que eles não são particulares, privados. São Gerais, são comuns". (GONÇALVES, 2000, p.24). Nessas paisagens fitogeográficas já existiam formas e maneiras de manejar os seus recursos. Quando Ribeiro (2005) ressalta a importância das "Florestas Anãs", ele cita uma passagem de Saint-Hilaire (1975b) que registrou em sua viagem pelo sertão no início do século XIX, elementos de manejo do Cerrado, dizendo, "Como o fogo consome o capim dos pastos com grande rapidez, ele não chega a queimar o tronco das árvores espalhadas pelos tabuleiros cobertos. Apenas deixa-as enegrecidas e resseca suas folhas, as quais logo brotam de novo" (SAINT-HILARIE, 1975b, apud RIBEIRO, 2005). Uma curiosidade dessa passagem de viagem, também é o registro da presença da unidade geomorfológica de denominação tabuleiro, nome também dado ás nossas chapadas, aqui no norte de Minas Gerais.

Desses tempos de povoamento pelo território do interior para cá, muitas mudanças aconteceram, principalmentecom as propostas políticas de desenvolvimento ocorridas em meados do século XX, como a Revolução Verde. As relações espaciais e "modelos' de usos da terra são diversos, como afirma Stralen (1980, p.35), citado por Brito (2006), que "[...] no norte de Minas, o processo de ocupação formou o que ele chama de "binômio latifúndio-minifúndio". Para Brito (2006, p.227), ele explica que, "da mesma forma que se encontram grandes propriedades muitas vezes pouco exploradas, encontram-se pequenas áreas muito exploradas, com o uso de força de trabalho familiar". Junto com as propostas existem os pacotes de monoculturas, projetos de irrigação e espoliação das terras dos pequenos agriculturores. Para Fonseca (2014, p.42), "O cerrado, cobertura vegetal encontrada em grandes áreas do Norte de Minas, sofreu com essa mecanização intensa" ; mas também apresenta o rural que se mostra como paisagem dominante, visto que a maioria dos municípios são eminetemente rurais (FONSECA, 2012).

O exemplo que trazemos é a comunidade de Vereda Funda no município de Rio Pardo de Minas (MG). Em Vereda Funda a prática e concepção deluta e resistência pelas terras dos gerais apresenta várias estratégias. As conferências locais e regionais, denominadas de Conferências Geraizeiras, aconteceram nos anos de 2006 e 2007. A Conferência de 2007 com a temática "Terras públicas e Território Geraizeiro: juntos na defesa do Território", apresentou proposta de criação de Reservas Extrativistas-RESEX's, para conciliar a inclusão das populações tradicionais e a conservação da natureza. Nos municípios vizinhos, como em Grão Mogol, essa corrente de concepção e práticas de reuniões, acontece no assentado de Americana, pois apesar das peculiaridades e especifidades políticas, algumas das reivindicações são comuns, assim como as várias problemáticas e convivências de manejo.

A institucionalização ${ }^{10}$ por parte de associações, sindicatos rurais e organizações não-governamentais, tem sido utilizado como estratégia de resistência nas lutas

\footnotetext{
9 RIBEIRO, Ricardo Ferreira. Florestas nas do Sertão - O Cerrado na História de Minas Gerais. Belo Horizonte: Autêntica, 2005. Vol .I

10 Pode-se destacar aqui o CAA/NM- Centro de Agricultura Alternativa Norte-Mineiro; a Rede Cerrado em nível nacional; a Comissão da Pastoral da Terra - CPT/BA e outras mais.
} 
pelos direitos e acessos às políticas e o empoderamento coletivo. É de suma importância destacar que a Agricultura Familiar soma-se também como parte do fortalecimento "dos de dentro" em enfrentar as ameaças "dos de fora". Em conjunto com a agricultura, soma-se a educação que de maneira singular afirma a posição geográfica, política, ambiental, econômica e cultural dos meios sustentáveis e busca de qualidade de vida dessas comunidades geraizeiras. Muitas delas apresentam às Escolas ${ }^{11}$ Família Agrícola-EFA, que ajudam a firmar o propósito da luta, assim como de maneira objetiva e convincente estabelecem e ampliam as possibilidades de um mundo melhor para às futuras gerações, antes visto como um caminho "utópico". Na condição econômica, o vínculo com a saúde estabelece-se e soma-se, pois se destaca a segurança alimentar que interdepende dessas duas condições. Para Fonseca (2014, p.122) "A nova Lei Federal $11.947 / 2009$ exige que pelo menos $30 \%$ dos produtos adquiridos para a alimentação dos estudantes com recursos do Fundo Nacional de Desenvolvimento da Educação - FNDE - sejam provenientes da agricultura familiar."

Em oposição à monocultura de eucalipto com grande predominância regional,o manejo de destaque é o agroecológico, retratado da seguinte maneira:

Os princípios agroecológicos estão totalmente integrados aos modos de produção do geraizeiro, compondo o conjunto multifuncional da agricultura familiar, com destaque, neste estudo, para as funções sociais, ambientais, econômicas e culturais, ensejando, assim estratégias de terrritorialidade, cuja reprodução está ancorada na manutenção dos quintais ecológicos, dos Sistemas Agroflorestais- SAFs - e da agrossilvicultura, que permitem a manutenção dessas famíliasque estão contidas numa proposta de reterritorialização pela reconversão agroextrativista em áreas que, outrora, the foram expropriadas em favor do grande capital e da monocultura. (GOMES; FONSECA, 2013, p.113)

A multifuncionalidade exercida pelos geraizeiros em seu "habitat" vem de encontro com a condição de sustentabilidade, muitas das vezes amplamente controversa em algumas linhas do pensamento ecológico e/ou ecologista. Mas no passado exitiam inúmeras maneiras de "verificar" às várias possibilidades no meio ambiente rural. "Para que os mesmos garantam suas reproduções, os cerrados com seus tabuleiros, espigões e chapadas fazem parte da estratégia produtiva fornecendo, por meio do extrativismo, forragem para o gado, caça, madeira, frutos, folhas, mel e medicamentos". (COSTA, 2005, p. 302). O autor já identificava razões da multifuncionalidade por domínios dos gerais, muito antes da condição dessa categoria e prática constituirse como usual, pois o autor remete aos processos de povoamento pelo sertão dos gerais. A condição multifuncional da atualidade remete de maneira ampla o mundo rural:

O crescimento mundial do fenômeno das atividades nãoagrícolas no rural, traduzidos no conceito de pluriatividade fez com que o espaço rural deixasse de ser associado somente ao agrícola, de modo que as atividades não-agrícolas levaram os agricultores a ter "novas" funções econômicas e sociais. Com maior interesse pelo "mundo" rural, há uma complexificação de objetostécnicos e de ações no campo, que levam a necessidade de apreensão das múltiplas funções da agricultura. (CANDIOTTO, 2009, p.1)

11 Além das Escolas, existem também os programas e projetos, como o caso do PRONERAPrograma Nacional de Educação na reforma Agrária, da Universidade Estadual de Montes Claros/ Unimontes. 
É nessa condição dos complexos do mundo vivido que homens e mulheres simples exercem suas subjetividades e revelações de práticas de saberes e fazeres por todo o Gerais.

\section{CONSIDERAÇÕES FINAIS: PROSAS QUE AINDA INCOMODAM...}

Articular ${ }^{12}$ e resistir são verbos empregados constantemente no discurso das identidades sertanejas. Mesmo que a "Análise desse Discurso" possa ser identificada ou reconhecida como negativa para tais povos, o movimentoe a dinâmica de luta são fundamentais para a manutenção de suas identidades. Os indígenas Xakriabá juntamente com os negros de quilombos, associados aos geraizeiros comungam da identidade sertaneja e da história salvaguardada em seus constumes, patrimoniada nas formasde saberes e fazeres.

Mesmo nas ações locais, a pluralidade demandada converge para a formação cidadã e de reconhecimento de suas instituições no campo das estratégias sociais, econômicas, ambientais e políticas.

O exercício das práticas comunitárias e de organizações sociais faz com que a preservação e conservação dessa cultura prevaleçam diante das adversidades do capital e da modernidade que diante do seu "tempo rápido", contradiz com "tempo lento ${ }^{13 "}$ das pessoas por entre esse sertão.

A sustentabilidade da vida diante das práticas de convivências; a segurança alimentar; o conhecimento do patrimônio genético e a biodiversidade no Cerrado e na Caatinga fortalecem e comungam para um futuro melhor.

A justiça social frente aos direitos reconhecidos e estabelecidos pode aprimorar ás virtudes de grupos socialmente organizados que lutam pela condição de "ser" para além de "ter". A visibilidade das normas e legislações pode contribuir para o empoderamento diário, mesmo que por formação de juristas leigos ${ }^{14}$, como mencionado por Santos (2007).

O conflito entre a tradição e a modernidade estará em constante "assimilação" de um pelo outro. Talvez sejam partes de um mesmo inteiro, ou completam-se...

\section{REFERÊNCIAS}

ALMEIDA, Maria Geralda. (Org.). Geografia e Cultura: os lugares da vida e a vida dos lugares. Goiânia: Editora Vieira, 2008. p.313.

ANAI-Associação Nacional de Ação Indigenista -BRA/13/19 - Implementação da PNGATI - Plano de Gestão Territorial e Ambiental das Terras Indígenas do Povo Xakriabá e relato das atividades de planejamento, - Produto $1 ; 2 ; 3$. Salvador /BA: 2016.

12 Com base na institucionalização da Articulação Rosalino que abarca tanto os povos Xakriabá, Quilombolas e Geraizeiros.

13 Milton Santos (1996), com base na Psicosfera e Tecnosfera.

14 SANTOS, Boaventura de Sousa. Para uma revolução democrática da justiça. São Paulo: Cortez, 2007, $120 \mathrm{p}$. 
BRANDÃO, Carlos Rodrigues. No rancho fundo: espaços e tempos no mundo rural. Uberlândia: EDUFU, 2009.

BRASIL, Decreto no 7.747, de 5 de Junho de 2012 - Política Nacional de Gestão Territorial e Ambiental de Terras Indígenas - PNGATI. Presidência da República - Casa Civil - Subchefia para Assuntos Jurídicos, 2012.

BRITO, Izabel Cristina Barbosa. Monocultura do eucalipto e expropriação das populações tradicionais no norte de Minas Gerais. In: FEITOSA, Antônio Maurílio; ZUBA, Janete Aparecida Gomes; CLEPS JUNIOR, João. Debaixo da lona: tendências e desafios regionais da luta pela posse da terra e da reforma agrária no Brasil. Goiânia: Ed da UCG, 2006.p.221-253.

CANDIOTTO, Luciano Zanetti Pessôa. Aspectos Históricos e Conceituais da Multifuncionalidade da Agricultura. Anais, XIX - ENCONTRO NACIONAL DE GEOGRAFIA AGRÁRIA, São Paulo, 2009, p.1-16.

CLASTRES, Pierre. A Sociedade contra o Estado: pesquisas de antropologia política. Tradução Theo Santiago. São Paulo: COSAC NAIFY, 2003. 280p.

COSTA, João Batista de Almeida. CULTURA Sertaneja: a conjungação de lógicas diferenciadas. In: SANTOS, Gilmar Ribeiro dos (Org.). Trabalho, Cultura e Sociedade no Norte/Nordeste de Minas: considerações a partir das Ciências Sociais. Montes Claros: Best Comunicação e Marketing, 1997. p. 77-97.

COSTA, João Batista de Almeida. Cerrados Norte Mineiro: Populações Tradicionais e suas identidades territoriais. In: ALMEIDA, Maria Geralda. (Org.). Tantos Cerrados: múltiplas abordagens sobre a biodiversidade e singularidade cultural. Goiânia: Editora Vieira, 2005. p.295-319.

FERNANDES, Bernardo Mançano. Conflitualidade e Desenvolvimento Territorial. In: Antônio Márcio Buainain (coord.) et al. Luta pela terra, reforma agrária e gestão de conflitos no Brasil. Campinas, SP: Editora da UNICAMP, 2008. p.173-230.

FONSECA, Ana Ivania Alves; ALVES, Genilda do Rosário; AYRES, Eduardo Charles Barbosa; FONSECA, Vanessa. Estratégias e Organização das Populações tradicionais no norte de Minas Gerais. In: FERREIRA, Darlene Aparecida de Oliveira; FERREIRA, Enéas Rente ; MAIA, Adriano Corrêa. (Org.) Estudos Agrários: a complexidade do Rural Contemporâneo. São Paulo: Cultura Acadêmica, 2011. p. 305-320.

FONSECA, Ana Ivania Alves. Agricultura Familiar como sustentabilidade: Estudos de Caso do Planalto Rural de Montes Claros/MG. 181 fls. Instituto de Geociências Exatas da Universidade Estadual Paulista Júlio de Mesquita Filho, Rio Claro. 2012. (Tese de Doutorado em Geografia).

FONSECA, Ana Ivania Alves. Agricultura Familiar como sustentabilidade: Estudos de Caso do Planalto Rural de Montes Claros/MG. Montes Claros: Unimontes, 2014.

GIDDENS, Anthony. O Estado-nação e a violência. Segundo volume de uma crítica contemporânea ao materialismo histórico. Tradução Beatriz Guimarães. São Paulo, Edusp, 2001. 374p. (Clássicos, 22).

GONÇALVES, Carlos Walter Porto. As Minas e os Gerais: Breve Ensaio sobre Desenvolvimento e Sustentabilidade a partir da Geografia do Norte de Minas. In: LUZ, Claúdia; DAYRELL, Carlos (Org.). Cerrado e Desenvolvimento: Tradição e Atualidade. Montes Claros: Imprensa Universitária da Unimontes, 2000. p19-45.

GOMES, Leonardo Ferreira; FONSECA, Ana Ivania Alves. Os Geraizeiros. In: Estudos sobre Agroecologia, Agricultura Familiar e as territorialidades no Norte de Minas Gerais. (Org.) FONSECA, Ana Ivânia Alves [et al.]. Montes Claros: Unimontes, 2013. p.111-155. 
HAESBAERT, Rogério. O mito da desterritorialização. Rio de Janeiro: Bertrand Brasil, 2004. 395p.

Instituto Brasileiro de Geografia e Estatística-IBGE. Os indígenas no Censo Demográfico 2010-primeiras considerações com base no quesito cor ou raça. Ministério do Planejamento, Orçamento e Gestão/Diretoria de Pesquisas. Rio de Janeiro: 2012, p. 5. Disponível em: <http://www.ibge.gov.br/indigenas/ indigena_censo2010.pdf>. Acesso em: 15 dez. 2012.

PNGATI - Plano de Gestão Territorial e Ambiental das Terras Indígenas do Povo Xakriabá e Xakriabá Rancharia - Produto 3 - BRA/13/019 - Implementação da PNGATI (2016, p.42)

RIBEIRO, Ricardo Ferreira. Florestas nas do Sertão - O Cerrado na História de Minas Gerais. Vol. I . Belo Horizonte: Autêntica, 2005.

SALGADO, Hebert Canela. Brejos dos Crioulos no sertão norte mineiro: desordem e rearranjos em territórios relacionais. 2015. 737 fls. (Tese de Doutorado). Universidade Federal de Uberlândia, Programa de Pós-Graduação em Geografia. Uberlândia. 2015.

SANTOS, Ana Flávia M. Do terreno dos caboclos do Sr. São João à terra indígena Xakriabá: as circunstâncias da formação de um povo. Um estudo sobre a construção social de fronteiras. Programa de Pós-Graduação em Antropologia Social do Departamento de Antropologia da Universidade de Brasília, (Dissertação de Mestrado). Brasília-DF. 1997.

SANTOS, Boaventura de Sousa. Para uma revolução democrática da justiça. São Paulo: Cortez, 2007.

SANTOS, Milton de Almeida. Por uma Geografia Cidadã: por uma epistemologia da existência. Boletim Gaúcho de Geografia - 21:7-14. Agosto de 1996 - p. 7-14. Associação Brasileira de Geógrafos, Seção Porto Alegre, Porto Alegre, RS, Brasil. (Versão online disponível em: http://seer.ufrgs.br/bgg/article/view/38613/26350).

SILVA, Cássio Alexandre. A natureza de um território no sertão do norte de Minas Gerais: a ação territoriar dos Xakriabá. 2014. 267 fls. (Tese de Doutorado). Universidade Federal de Uberlândia, Programa de Pós-Graduação em Geografia. Uberlândia. 2014. 